\title{
Discussing Active Learning from the Practitioner's Perspective
}

\author{
Priscilla Bamba
}

The purpose of this paper is to present an overview of how active learning took place in a class containing specific readings, cooperative and collaborative group work, and a writing assignment for college students at a Northern Virginia Community College campus (NVCC). Requisite knowledge, skills, learner characteristics, brain-based learning, and the active learning environment in relation to motivation and participation, as well as the transfer of learning, are also discussed from a practitioner's stance. Learning is a process the individual actively discovers and builds on previous knowledge through a progression of carefully planned activities. The lesson model followed was that of Madeline Hunter (1994) (see Appendix A), but more current research, such as that of Dawes and Larson (2011) and Yoders (2014), is also used.

When developing unit and lesson plans, practitioners must be knowledgeable about learning theories and teaching objectives in order to maximize student experiences (Yoders, 2014) and learning performance (Klymchuk, 2014). The following paper displays a lesson plan containing a series of assignments (see Appendix A) as part of a unit of study plan for a college-level writing class at Northern Virginia Community College (NVCC). This lesson was presented in the Madeline Hunter lesson plan format. The Madeline Hunter lesson plan method describes a seven-step approach to direct instruction in which active learning performance depends on student control (Hunter, 1994; Hunter \& Barker, 1987; Wolfe, 1998). The issues of student motivation and participation, brain-based learning, the transfer of learning, hybrid-course applicability to the English as a Second Language (ESL)/English Language Learner (ELL), and the application of the lesson by the practitioner are discussed.

\section{DESCRIPTION OF LESSON PLAN}

The goal of this lesson (see Appendix A) was to provide students with an appropriate learning environment or instructional setting (Sitzmann \& Johnson, 2012), instructional tools, and guidelines in order to acquire the necessary skills to write a definition paper. Students participated in a face-toface $(\mathrm{F} 2 \mathrm{~F})$ learning environment that allowed for their self-direction identified in a blended learning space through choice of activities and discussion topics presented by the practitioner. The class also incorporated an online component for their sharing of ideas and collaborating outside class. The lessons incorporated brain-based learning and motivational activities as explained by Degen (2014).

At the end of the lesson, students should have been able to write a definition paper that used facts to explain a situation or topic. The writer was instructed to refrain from using emotional or reflective language and not to express his or her personal opinion. It was important that the practitioner helped the student move from self-expression that might include first and second person pronoun usage. The first and second person focus was permissible in the rough-draft stage but moved to definition and fact-supported writing in third person, which was the targeted final product. The student was to introduce the area to be defined and the direction of the paper, to provide supporting evidence from the literature, and to conclude by summarizing the main ideas and their relationships.

\section{PROCEDURES}

The students were largely in their mid-twenties with only a few students up to ten years older. They were roughly half women and half men of a variety of ESL backgrounds. Their geographical 
location was within the state of Virginia and the students attended an NVCC community college campus; they were included in medium- to low-income economic status. The students were required to follow systematic procedures and participate in all individual and team learning activities, involving both an online Moodle (Beatty \& Ulasewicz, 2006; Dougiamas, 1999; Lavigne, Díaz López, Salas, \& Sandoval, 2013) and the F2F classroom. The practitioner provided online discussion prompts for student response and discussion. Students were to discuss the topics and definitions in the online forums as they wrote their essays.

Students were given a prewriting activity in the classroom using a jigsaw puzzle in which they were divided into main groups and then sub-divided to work in other teams to share their parts of the puzzle (Ghaith \& El-Malak, 2004; Goddard, Wood, O'Shea, \& Toohey, 2014). The puzzle was a passage divided into paragraphs according to the number of teams. Each team received one paragraph from the passage. They each learned their part and then subdivided into other teams, shared and learned each of the other teams' paragraphs, went back to their original teams, and then tried to piece the information together as a whole passage. The first team that got the entire passage ready was the winning team. Teams were assessed for team spirit and outcomes, and finally the class as a whole received the entire, fitted-together essay. The collaborative and competitive element was a stimulating part of the process, and, as pointed out by Pinheiro and Simoes (2012), active learning through such an environment seemed to get students actively involved in their own learning process, especially when tasks involved an empirical component. Goddard et al. (2014) found that "student engagement increased from $20 \%$ to $70 \%$ in [team based learning]...with an increase in critical thinking skills and increased subject retention" (p. 29).

Next, the teams explained the organization of the essay by breaking it down into the introduction, body, and conclusion. When the team finished, the members decided on the kind of passage or mode of writing from a provided list. The passage was called a definition essay. One representative from each team explained the reasons for the team choice.
For homework, students collaborated online, chose a topic of interest, and defined a term, also from a provided list. They used instant messaging built into the online hybrid class, digital worksheets provided by the instructor, team forums, and telephone communication. They provided a definition of one of the following intangibles: love, justice, truth, freedom, diversity, success, intelligence, or family values. The team also was presented with the option of finding another definition for addiction such as people's addiction to dangerous relationships, overwork, consumerism, or soap operas. Next, the members collaboratively wrote a definition paper on a topic of their choice. Each member was assigned a role: topic researcher, first draft writer, writer, editor, and designer. The number of roles depended on the number of members on the team. Students were evaluated on the process, final writing assignment, and personal reflection. Regarding teamwork, the process included online forum discussions and class collaboration.

\section{PREREQUISITES AND PRIOR LEARNING}

Through a carefully devised process, all students whose native language was not English had to have undergone placement examinations after being accepted and enrolled into NVCC. All students (28 in total, 15 female and 13 male) were ESL or ELL. Upon a student's entering the freshman composition course, the practitioner was to assume that the knowledge, skills, and abilities (KSAs) of each student were on par with the average college student's abilities. Should the first class day's diagnostic writing reveal otherwise to the practitioner, he or she was obligated to refer that student to the proper individuals or administrative office for a transfer to an ESL or developmental course. This action ensured the student had sufficient time to obtain the necessary KSAs to be able to function in the college-level freshman English class.

\section{STUDENT MOTIVATION AND PARTICIPATION}

Since research as completed by Farrell and Weitman (2007) has shown that the most successful transfer of learning occurs when 'real-life' and active-learning situations are involved in a classroom, practitioners must strive to bring in personal experiences and observations as often as possible. 
As Tozer, Senese, and Violas (2006) purported, "To understand and nurture the learning potential of all students, [practitioners] need to understand the influences that culture and social class exert on both students and schools..." (p. 5). Furthermore, Dawes and Larson (2011) described how, in the selfdetermination theory, an activity in which students are engaged must be more than just meaningful or involve positive feelings; it must also involve the student's personally relating to the activity in a way that allows the self to become inextricably linked to the outcome. This is a deep level of involvement, and the practitioner must be aware and take part in that activity to ensure its success. The practitioner must challenge himself or herself with leveling positive reinforcement at every opportunity, even when students do not quite hit the mark of targeted achievement by building on the confidence of the student.

The Northern Virginia Community College (NVCC) system was the second largest and most diverse community college system in the US, with students from all over the world (Northern Virginia Community College, 2015). Additionally, many people attend community colleges first for financial reasons and then transfer later to universities, which are usually more expensive (Murray, 2010). At the time of this lesson, people from every socioeconomic background could be found on an NVCC campus. Following is a bulleted list of the popular discussion/presentation, cooperative learning activity that was used to bring people together, regardless of background, to encourage freedom of thought as long as the view was respectful and presented in a respectful manner.

- The class began by reading short stories, poems, or true anecdotal writings taken from the texts and news headlines, and then the class moved on to the personal experiences of students. The practitioner put students into groups of anywhere from three to five, and then each group had one of the writings to discuss for approximately 15 minutes. Then each member presented part of the story to the class.

- Each group took approximately 10 minutes to present (which means each person was expected to speak for five minutes or less). All questions from outside the presenting group were held until the presentation was finished, and all presentations were done in an informal manner, from the seated circle each group had formed. If several comments and debates occurred, sometimes the class ended and the assignment resumed in the next class.

- As facilitator, the practitioner ensured that each person in each group had something meaningful to add, even if the facilitator had to lead or prompt them with a few wellplaced questions and supportive assurances. Shy people were a little uncomfortable at first, but by the end of the discussion period, everyone became involved and often found that he or she had an opinion needing to be expressed.

- Differences of opinion within groups usually presented no problems and often made for a more lively presentation, since the first person presenting usually closed his or her talking points with a lead-in for his or her teammate, for example, "And I know that Karen has a different view, which she will now tell you about."

- Over a course of approximately six 90-minute class meetings, these discussion/debates led to in-class writings that were developed into drafts. Students then paired with someone in their group for critique feedback. Afterward, they were responsible for pairing with someone outside the group. The practitioner assisted in assigning the pairs when the students wished.

- At the end of the full-cycle of the paper, the student had input from at least two peers and the practitioner. They had also been required to do some research to generate support for the point of view presented. Sometimes this research took them into cultural investigation, since the feedback from the practitioner was for them either to substantiate or concede to an opposing viewpoint that might have been expressed in class. Sometimes students investigated together, if their topic and opinions allowed, and they experienced cooperative learning in an even greater capacity. The practitioner took notes carefully in these discussions, since he or she could not remember 
everything being said in the debates.

According to Pai (1990): "Culture plays a crucial role in determining what meanings people assign to their experiences, the contents of what is learned, as well as how learning occurs. Broadly speaking, teaching is nothing more than the facilitation of learning, and learning is at the heart of education" (p. 168).

Guss, Robinson, Funke, and Sorensen (2014) clarified that action theory and sociocultural theories state that knowledge passed from generation to generation is acquired and passed through social interactions; they purport that similar opportunities are offered and capitalized upon in learning environments. This means that it is up to the practitioner to ensure the comfort zone in the learning environment reaches and maintains maximum levels for students so some degree of off-task communication is engaged in, thus promoting socialization.

Therefore, a practitioner can observe that the students learn through transference that opinions are valid and dependent upon perspective. Students retain such information and lessons through their research and interest in proving or disproving what they have gained through their interaction with others of different backgrounds. Davidson and Major (2014) identified the differences in cooperative and collaborative learning, saying that each is distinct. However, they encouraged practitioners to explore both the similarities and differences in order to promote small group learning. These authors explained that cooperative learning relates more to students working together to help each other achieve independent goals. Collaborative learning, on the other hand, is when students work together toward a single goal. Either of these terms can relate to the theory constructivism in which students are the driving force behind several (if not all) of the aims and objectives in the assignment, but collaborative learning relates more to the objectives of the activities involved in this lesson.

McWey, Henderson, and Piercy (2006) stated, "Cooperative learning (CL) has been identified as an effective pedagogical strategy that promotes a variety of positive, cognitive, affective, and social outcomes" (p. 253). The positive and vigorous atmosphere in such classrooms captured and kept the interest of the students. They learned and could apply the learning later, far after they finished that particular class.

Some motivational and challenging activities with which practitioners might present students are as follows:

- The practitioner, as an enabler, challenges students to find things out for themselves (Chou \& Chou, 2011). For example, the practitioner can lead students by way of summarizing and generalizing inferences about a subject under discussion, involving the entire class. The practitioner would "encourage [students] to catch hold of ideas and 'run with them' beyond what is, as yet, known for sure" (Hyman, 1974, p. 73).

- The practitioner, through subtleties or through plain expression, conveys to the student that through the discussion method and the knowledge gained is its own reward. In other words, the intrinsic reward satisfies the internal drive that all animals (humans included) have to be competent in handling [the] environment (Hyman, p. 79).

- The practitioner strives to establish and maintain a positive interpersonal relationship with the students by becoming personally involved with each of them.

- The practitioner employs valuative discovery or valuative inquiry by asking students how they feel or what they think about matters such as social matters relative to the classroom-for example, by saying, "Let's see; your group was assigned to read 'Should Teenage Lawbreakers Be Jailed'? How do you feel about that?" Hyman, (p. 119).

\section{TRANSFER OF LEARNING}

In discussing the positive transfer of information and how it accelerates and promotes the transfer of learning, Hunter (1994) listed the tenets of producing effective examples as follows:

- Identify the essence of what is to be learned.

- Use examples from the students' own experiences.

- Check and eliminate any ambiguity within the examples.

- Avoid emotional or controversial overtones.

- Highlight critical attributes by obvious nonexemplars (pointing out what something is not).

- Analyze each example in advance (thinking 
on your seat is easier than thinking on your feet, as a practitioner).

- Introduce practitioner-generated examples first in order to set the tone and in case you must give all examples. (pp. 169-174)

Bedwell, Hunt, Touzel, and Wiseman (1984) provided the following list of instructional strategies as pathways to effective teaching, which should result in the transfer of learning for students:

- Guided Inquiry

- Lecture

- Demonstration

- Discussion Session

- Panel Discussion

- Laboratory

- Field Trip/Guest Speakers

- Instructional Game

- Drill (pp. 144-145)

Fendler (2012) described an intertwined relationship between all effective instructional strategies and psychology. In essence, the practitioner needs to understand and hold if not an empathetic nature at least a deep understanding and patience for the process by which students receive and retain information.

In preparing instruction, many items should be considered to foster learning and motivation among diverse learners. First to consider are students' socioeconomic backgrounds, their ethnicities, and their cultural beliefs. Studying the history of how different cultures approach learning and staying current to such matters can help a facilitator to be effective.

Next, it is important to take into consideration exposure gained to other cultures in travels if possible (for example, on trips or exchange programs) when choosing poetry, short stories, and anecdotal happenings from current news for studies. Al-Sharman and Siengsukon (2014) provided an explanation of the transfer paradox well worth considering: practitioners need to ensure that students are not just in training and learning to mimic and, perhaps of even greater importance, they should be allowed to absorb and exhibit what they learned; they should be experiencing active learning and true transfer of learning, so they can apply what they have learned in more complex or at least in different circumstances, but practitioners should be patient and not expect perfection. As Van Merrienboer, Kester, and Paas (2006) recommended, activities within cur- riculum should contain two complementary dimensions, as follows:

The first approach stresses that transfer may be partly explained by general or abstract knowledge that may be interpreted in the transfer situation (i.e. other use of the same-general-knowledge); the second approach stresses that transfer may be partly explained by the application of knowledge elements that are shared between the practice and the transfer situation (i.e. the same use of the same-specificknowledge). Instructional methods that explicitly aim at transfer of learning must carefully balance both complementary dimensions, and facilitate the interpretive aspects of knowing for those aspects of a complex task that are different from problem to problem and situation as well as facilitate the applicative aspects of knowing for those aspects of a complex task that are highly similar from situation to situation. (p. 346)

Baturay (2008) points out that if an instructional designer is held responsible for putting together curriculum, he or she might be lacking in expertise on the subject matter. Therefore, working in conjunction with a practitioner or group of practitioners is the most reasonable answer to decide on right topics and strategies. The overall plan, or the instructional systems design, involves the process by which the practitioner delivers the lesson plan. For this proposal and in a continuing fashion, practitioners need to become comfortable in the online environment in order to implement that component of the lesson successfully, too. This knowledge should involve workshops held in a timely fashion to update and improve upon that practitioner's knowledge.

The lesson discussed in this paper based the activities on constructivism, active learning, and social cognitive approaches to learning that incorporate brain-based research and information processing (Yoders, 2014). The cognitive approach to learning focuses on the learning process as an internal mental social state (Schunk, 2004). Learning is a process in which the learner actively discovers and builds on previous knowledge. The learner is an active participant in the process of learning and is not just acted upon by the environment. The opportunity to discuss the process of learning (metacognition) makes learning more meaningful and relevant to the learner (Schunk, 2004).

Brain-based learning deals with brain research and how it relates to classroom learning (Degen, 
2014) and learning and emotions (Jiwei, Qinghua, \& Haifei, 2014). The reading and writing assignment drew from a range of academic disciplines where students were able to demonstrate an understanding of plagiarism, use citations and references, locate peer-reviewed articles, write a literature review, think logically and independently, summarize peer-reviewed articles, detect mechanical, grammatical, and stylistic errors, and revise written work.

The lesson discussed in this paper also incorporated brain-based research in its instructional design (Degen, 2014) by making the online and classroom learning environments safe places for student learning. Through scientific testing, scientists now know that most learning takes place in the neo-cortex which does not function well when learners are under stress or fear (Aziz-Ur-Rehman, Malik, Hussain, Iqbal, \& Rauf, 2012; Wilson, 2005). Practitioners need to ensure that the classroom has a pleasant environment that is stress free for a relaxed atmosphere.

\section{CONCLUSION}

The development of lesson plans should be well-thought-out and should stem from learning and motivational theories (Colakoglu \& Akdemir, 2010). As found by Thomas and Quinlan (2014), when students are allowed the chances to be actively involved in their learning experiences, to self-direct with minimal facilitation by a practitioner, and to reflexively engage in both the process and the content of work produced, added value is the result to both the active learning and the resulting product, which were the same results found in this hybrid course assignment. Furthermore, wellstructured lesson plans guarantee successful learning (Dix \& Hughes, 2005). Activities included in a lesson can also stimulate drive, empowerment, and student motivation (Hull, 2007). In other words, when lessons are organized in not only a scholarly order but also a meaningful one by an attentive practitioner, students have the ability to think more clearly and make greater connections, resulting in more transfer of learning.

\section{References}

Al-Sharman, A., \& Siengsukon, C. F. (2014). Time rather than sleep appears to enhance off-line learning and transfer of learning of an implicit continuous task. Nature \& Science of Sleep, (6)27-36.doi:10.2147/NSS.S53789Aziz-Ur-Rehman, Malik, M. A., Hussain, S., Iqbal, Z., \& Rauf, M. (2012). Effectiveness of brain-based learning theory on secondary level students of urban areas. Journal of Managerial Sciences, 6(1), 113-122.

Baturay, M. H. (2008). Characteristics of basic instructional design models. Ekev Academic Review, 12(34), 471-482.

Beatty, B., \& Ulasewicz, C. (2006, July/August). Online teaching and learning in transition: Faculty perspectives on moving from Blackboard to the Moodle learning management system. TechTrends, 50(4), 36-46.

Bedwell, L. E., Hunt, G. H., Touzel, T. J., \& Wiseman, D. G. (1984). Effective teaching: Preparation and implementation. Springfield, IL: Thomas Publications.Chou, A. Y., \& Chou, D. C. (2011). Course management systems and blended learning: An innovative learning approach. Decision Sciences Journal of Innovative Education, 9(3), 463-484. doi:10.1111/j.15404609.2011.00325.x

Colakoglu, O. M., \& Akdemir, O. (2010). Motivational measure of the instruction compared: Instruction based on the ARCS motivation theory vs. traditional instruction in blended courses. Turkish Online Journal of Distance Education (TOJDE), 11(2), 73-89.

Davidson, N., \& Major, C. H. (2014). Boundary crossings: Cooperative learning, collaborative learning, and problem-based learning. Journal on Excellence in College Teaching, 25(3/4), 7-55.

Dawes, N. P., \& Larson, R. (2011). How youth get engaged: Grounded-theory research on motivational development in organized youth programs. Developmental Psychology, 47(1), 259-269.Degen, R. J. (2014). Brain-based learning: The neurological findings about the human brain that every teacher should know to be effective. Amity Global Business Review, (9)15-23.

Dix, G. \& Hughes, S. (2005). Teaching students in the classroom and clinical skills environment. Nursing Standard, 19(35). 41-47.

Dougiamas, M. (1999, June). Reading and writing for Internet teaching. Retrieved from http://dougiamas.com/writing/readwrite.html 
Fendler, L. (2012). The magic of psychology in teacher education. Journal of Philosophy of Education, 46(3), 332-351. doi:10.1111/j.1467-9752.2012.00865.x

Farrell, J. B., \& Weitman, C. J. (2007). Action research fosters empowerment and learning communities. Delta Kappa Gamma Bulletin, 73(3), 36-45

Ghaith, G. \& El-Malak, M. A. (2004). Effect of jigsaw II on literal and higher order EFL reading comprehension. Educational Research and Evaluations, 10(2), 105-115.

Goddard, A., Wood, C., O'Shea, M., \& Toohey, K. (2014). From passive to active learning: A case study using a modified team-based learning approach. Employment Relations Record, 14(1), 26-39.Guss, C. D., Robinson, B., Funke, J., \& Sørensen, J. (2014). Predicted causality in decision making: The role of culture. Frontiers in Psychology, (5)1-4. doi:10.3389/fpsyg.2014.00479

Hull, C. (2007). Drive reduction theory. Retrieved from http://www. lifecircles-inc.com/Learningtheories/behaviorism/clarkhull. $\mathrm{html}$

Hunter, M., \& Barker, G. (1987, October). "If at first...": Attribution theory in the classroom. Educational Leadership, 45(2), 5054.

Hunter, M. (1994). Enhancing teaching. New York: Macmillan College Publishing.

Hyman, R. T. (1974). Ways of teaching. Philadelphia, PA: J. B. Lippincott Company.

Jiwei, Q., Qinghua, Z., \& Haifei, L. (2014). A study of learner-oriented negative emotion compensation in e-learning. Journal of Educational Technology \& Society, 17(4), 420-431.

Klymchuk, V. (2014). The motivational dimensions of life events' perception: Towards an individual motivational mapping on self-determination theory basis. Education Sciences \& Psychology, 28(2), 78-92.

Lavigne, G., Díaz López, K. M., Salas, L. M., \& Sandoval, J. O. (2013). Learning and navigating: An exploratory study of the relationships between learning styles and navigational practices in Moodle. RUSC: Revista De Universidad Y Sociedad Del Conocimiento, 10(2), 328-343. doi:10.7238/rusc. v10i2.1402

McWey, L. M., Henderson, T. L., \& Piercy, F. P. (2006, April). Cooperative learning through collaborative faculty-student research teams. Family Relations, 55(2), 252-262.
Murray, C. (2010). Time, effort, and care: The challenge of retaining students until they meet their academic goals. Community College Journal, 80(4), 34-35.

Northern Virginia Community College (2015). About NOVA. Retrieved February 29, 2015 from http://www.nvcc.edu/ about-nova/ Pai, Y. (1990). Cultural foundations of education. Columbus, OH: Merrill Publishing.

Pinheiro, M. M., \& Simoes, D. (2012). Constructing knowledge: An experience of active and collaborative learning in ICT classrooms. Turkish Online Journal of Educational Technology-TOJET, 11(4), 382-389.

Schunk, D. (2004). Learning theories: An educational perspective (4th ed.). Upper Saddle River, NJ: Prentice Hall.

Sitzmann, T., \& Johnson, S. K. (2012). The best laid plans: Examining the conditions Under which a planning intervention improves learning and reduces attrition. Journal of Applied Psychology, 97(5), 967-981. doi:10.1037/a0027977

Thomas, R., \& Quinlan, E. (2014). Teaching and learning focus group facilitation: an encounter

with experiential learning in a graduate sociology classroom. Transformative Dialogues: $\quad$ Teaching \& Learning Journal, 7(1), 1-15. Tozer, S. E., Senese, G., \& Violas, P. C. (2006). School and society: Historical and contemporary perspectives (5th ed.). Boston, MA: McGraw-Hill.

Van Merrienboer, J. Kester, L, \& Paas, F. (2006, April). Teaching complex rather than simple tasks: Balancing intrinsic and germane load to enhance transfer of learning. Applied Cognitive Psychology, 20(3), 343-352.

Wilson, L. O. (2005). Wilson's newer views of learning: Using brain-based education to optimize learning - some helpful hints. Retrieved from http://thesecondprinciple.com/optimallearning/usingbrainbasededucation/

Wolfe, P. (1998, November). Revisiting effective teaching. Educational Leadership, 56(3), 61-65. Yoders, S. (2014). Constructivism theory and use from 21st century perspective. Journal of Applied Learning Technology, 4(3), 12-20. 


\section{Appendix A}

\begin{tabular}{|c|c|}
\hline \multicolumn{2}{|r|}{ The Madeline Hunter Model } \\
\hline $\begin{array}{l}\text { What is the } \\
\text { lesson objective? }\end{array}$ & $\begin{array}{l}\text { Students will be able to write a definition paper that uses facts } \\
\text { to explain a situation or topic. The students will refrain from } \\
\text { using emotional or reflecting language and will not express } \\
\text { their personal opinions. The students will introduce the area to } \\
\text { be defined and the direction of the paper, provide supporting } \\
\text { evidence from the literature, and conclude by summarizing the } \\
\text { main ideas and their relationships. }\end{array}$ \\
\hline $\begin{array}{l}\text { Standards } \\
\text { addressed and } \\
\text { expectations of } \\
\text { students: }\end{array}$ & $\begin{array}{l}\text { Students will apply APA standards for style, grammar, citations, } \\
\text { and references. }\end{array}$ \\
\hline Anticipatory Set: & $\begin{array}{l}\text { Have you ever-encountered difficulties in following a } \\
\text { conversation, lecture, or reading passage? Why? What would } \\
\text { have made the content easier to comprehend? }\end{array}$ \\
\hline $\begin{array}{l}\text { Teaching/ } \\
\text { Instructional } \\
\text { Process: }\end{array}$ & $\begin{array}{l}\text { The students will follow systematic procedures and participate } \\
\text { in all the individual and team learning activities both online } \\
\text { Moodle (Beatty \& Ulasewicz, 2006; Dougiamas, 1999) and in } \\
\text { the classroom. The practitioner will provide online discussion } \\
\text { questions for students to respond and discuss. Students will } \\
\text { discuss the topics and definitions in the online forums as they } \\
\text { write their essays. } \\
\text { Students will have a prewriting activity in the classroom using } \\
\text { a jigsaw puzzle where they are divided into main and then sub- } \\
\text { divided to work in other teams to share their part of the puzzle } \\
\text { (Ghaith \& El-Malak, 2004). The puzzle is a passage divided } \\
\text { into paragraphs according to the number of teams. Each team } \\
\text { will receive one paragraph from the passage. They each will } \\
\text { learn their part and then subdivide into other teams, teach and } \\
\text { learn each of the other teams' paragraphs, go back to their } \\
\text { original teams and try and piece the information as a whole } \\
\text { passage. The first team to get the whole passage ready will be } \\
\text { the winning team. Teams will be assessed for team spirit and } \\
\text { outcomes. The teams will receive the whole essay. } \\
\text { Next, the teams will explain the organization of the essay by } \\
\text { breaking it down into the introduction, body, and conclusion. } \\
\text { When the team finishes, the members will decide on the kind } \\
\text { of the passage. The passage is called a definition essay. One } \\
\text { representative from each team will explain the reasons for the } \\
\text { team's choice. }\end{array}$ \\
\hline $\begin{array}{l}\text { Guided practice } \\
\text { and monitoring: }\end{array}$ & $\begin{array}{l}\text { Student will be monitored using Moodle online interface. } \\
\text { Student will receive online peer and practitioner feedback for } \\
\text { their writing. } \\
\text { Students will be evaluated on the process, final writing } \\
\text { assignment, and personal reflection. The process will include } \\
\text { the online forum discussions and class collaboration on } \\
\text { the teamwork. Students' writing assignment will be graded } \\
\text { according to the assessment rubric in the course syllabus. }\end{array}$ \\
\hline Closure: & Why is it necessary to provide a definition? \\
\hline
\end{tabular}

\begin{tabular}{c|l}
\hline $\begin{array}{c}\text { Independent } \\
\text { Practice: }\end{array}$ & $\begin{array}{l}\text { For homework, students will collaborate online, choose a topic } \\
\text { of interest, and define a term. They may provide a definition } \\
\text { of one of the following: love, justice, truth, freedom, diversity, } \\
\text { success, intelligence, or family values. The team may choose to } \\
\text { find another definition for addiction such as people's addiction } \\
\text { to dangerous relationships, overwork, consumerism, or soap } \\
\text { operas. } \\
\text { Next the members will write a definition paper on a topic } \\
\text { of their choice. Each member will be assigned a role: topic } \\
\text { researcher, first draft writer, writer, editor, and designer. The } \\
\text { number of roles will depend on the number of members on } \\
\text { the team. }\end{array}$ \\
\hline Materials & $\begin{array}{l}\text { The practitioner will present the information and instructions } \\
\text { visually via a PowerPoint presentation using a multimedia } \\
\text { computer projector. Students will need access to a Microsoft } \\
\text { Word processor, an Internet connection, and access to the } \\
\text { class password protected Moodle Web site. A full list of course } \\
\text { books will be available in the course outline. }\end{array}$ \\
\hline Duration & \begin{tabular}{c} 
90 minutes \\
\hline
\end{tabular}
\end{tabular}

\section{Author Biography}

Dr. Priscilla Bamba is a fulltime, online instructor in the English Department of the College of Humanities and Social Sciences at Grand Canyon University. She joined the university last year, moving there the northern Virginia area. Originally from Kentucky, she holds doctorate is in Educational Leadership: Curriculum and Instruction from the University of Phoenix. Her Bachelor's and Master's degrees are from Eastern Kentucky University, both in English and Humanities. She has more than three decades of experience in higher education, including several years of traveling and teaching in other countries, including Japan, South Korea, Pakistan, and Australia.

She currently lives in Tempe, Arizona, with her husband, her son, and two cats. She enjoys working for Grand Canyon University and the highly personal model the university uses to work with the students, incorporating a spiritual element into its structure. This educational model is the one she believes promotes a most comfortable environment for students to grow and flourish. 